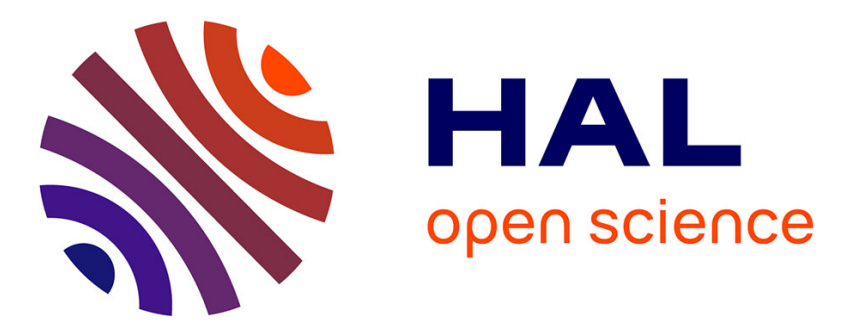

\title{
Implementation of Control Strategy for Step-down DC-DC Converter Based on Piezoelectric Resonator
}

Mustapha Touhami, Ghislain Despesse, François Costa, Benjamin Pollet

\section{To cite this version:}

Mustapha Touhami, Ghislain Despesse, François Costa, Benjamin Pollet. Implementation of Control Strategy for Step-down DC-DC Converter Based on Piezoelectric Resonator. 2020 22nd European Conference on Power Electronics and Applications (EPE'20 ECCE Europe), Sep 2020, Lyon, France. pp.1-9, 10.23919/EPE20ECCEEurope43536.2020.9215910 . hal-02978536

\section{HAL Id: hal-02978536 \\ https://hal.science/hal-02978536}

Submitted on 26 Oct 2020

HAL is a multi-disciplinary open access archive for the deposit and dissemination of scientific research documents, whether they are published or not. The documents may come from teaching and research institutions in France or abroad, or from public or private research centers.
L'archive ouverte pluridisciplinaire HAL, est destinée au dépôt et à la diffusion de documents scientifiques de niveau recherche, publiés ou non, émanant des établissements d'enseignement et de recherche français ou étrangers, des laboratoires publics ou privés. 


\title{
Implementation of Control Strategy for Step-down DC-DC Converter Based on Piezoelectric Resonator
}

\author{
Mustapha TOUHAMI $^{(1)}$, Ghislain DESPESSE ${ }^{(1)}$, François $\operatorname{COSTA}^{(2),(3)}$ and Benjamin \\ POLLET. \\ (1) CEA, LETI, Minatec Compus, Université de Grenoble Alpes, 17 avenue des martyrs, \\ 38054 Grenoble, France. \\ (2) Université Paris-Saclay, ENS Paris-Saclay, CNRS, SATIE, 91190, Gif-sur-Yvette, \\ France, \\ (3) Université Paris Est Créteil, 94010, Créteil France. \\ E-Mail: mustapha.touhami@cea.fr, Ghislain.Despesse@,cea.fr, \\ francois.costa@satie.ens-cachan.fr,benjamin.pollet.p@gmail.com. \\ URL: http://www.leti-cea.com.
}

\section{Keywords}

«DC-DC converter», «Power conversion», «Piezoelectric Resonator», «Soft Switching», «Control Strategy».

\begin{abstract}
With the growth in demand for miniaturization in power electronics, the current solutions are starting to display their limits in dimensions, power densities and efficiency. To meet the previous demands, the new piezoelectric materials achieving high power densities and efficiency could be the solution to ensuring the requirements. The piezoelectric resonators (PRs) and the piezoelectric transformers (PTs) have been used previously. Unlike the PTs, the use of PRs in power electronics has not been fully explored, and their use has been limited to operating as switched capacitors. However, a new operating principle using PRs based on energy and electrical balance exhibits good performances in steady state. In this paper, our motivation is to investigate in the capability to control a de-de converter based on PRs using this operating principle. Indeed, this paper presents the control strategy of a new step-down DC-DC converter based on a piezoelectric resonator (PR), which is used as an energy storage element. The operating principle of the converter is also presented. Moreover, the control algorithm has been implemented in field programmable gate array (FPGA) to regulate the output voltage. The control principle is validated experimentally for input-output voltages 120 - $48 \mathrm{~V}$, and achieving an efficiency up to $94 \%$ for large operating power range.
\end{abstract}

\section{Introduction}

In last decades, miniaturization, integration and high power densities became a serious challenge for power electronics designers. Various solutions on power electronics have been proposed for these objectives using magnetic components, switched capacitors and variable capacitors [1-3]. Magnetics components are widely used in power electronics, but their integration on silicon is difficult and the performances become limited by magnetic core at high frequency [1]. Variable capacitor converters can be integrated on silicon but need high chip area, and their efficiency is sensitive to load variations [2-3]. Concerning switched capacitor converters, their operations are limited to specific output/input voltages ratios [4].

To overcome the abovementioned limits of traditional solutions, an alternative storage technique is emerging. It is based on piezoelectric resonators (PRs) or piezoelectric transformers (PTs) which store the transient energy in a mechanical form. Indeed, the piezoelectric components can offer a high quality factor (up to 2000 inducing low losses), and it can operate at high frequency (up to $30 \mathrm{MHz}$ or more 
inducing a high power densities). Their integration on silicon is widely achieved and continuously improved [5-6]. In addition, the low profile of piezoelectric components can be interesting for integrated converters in thin devices as smartphones, laptops and other connected things (IoT). In literature, most of the proposed converter topologies use PTs in order to replace the magnetic transformers, but these topologies need an additional inductor to increase their performances [7]. So, suppressing this additional inductor in such converters is the aim of several research works [8-13].

In this paper, we present a new conversion principle and our DC-DC converter-using PRs that operate on energy and electrical charges balancing over a mechanical resonant period of the piezoelectric material. The conversion cycle is composed of six steps, which alternate constant voltage steps (connected PRs to a voltage level), and constant electrical charge ones (isolated PRs). In fact, in steady state, the PR takes energy from the input source equal to the one restituted to the output load plus the one dissipated, maintaining mechanical oscillations of constant amplitude. The energy exchange operates during the constant voltage steps. Therefore, the isolated stages (constant charge operation) allow natural evolving of the PR's voltage up to the next constant voltage level. This enables to operate with zero voltage switching (ZVS), leading to reduce power losses and EMI level [14]. A full design of step down DC-DC converter based on a similar principle is presented in [9-10]. The concept is validated by simulation and experiments with efficiency up to $98.4 \%$ at $160 \mathrm{~mW}$ for low voltage conversion [910]. Recently, various topologies are presented based on the similar principle [10]. The first results show good performances in terms of power densities and efficiency for low power conversion and expect to be competitive compared with traditional converters.

The main objective of this paper is to introduce a new topology of DC-DC converter dedicated to applications at low output/input voltage ratio and its related control strategy. This paper demonstrates the feasibility of controlling a DC-DC converter based on PR, which operates on a six phases conversion cycle. The aim of this control is to regulate the output voltage, ensuring the soft switching and the energy balancing. The load variation should also be compensated. This paper is organized as follows: in the first part, we present the new topology of the converter and the operating principle. In the second part, we analyze and identify the various parameters aiming to control the energy balance and to regulate the output voltage. Then, we present the regulation mechanism for each control parameter. In the experimental results part, we exhibit our prototype, and the dynamic response for $V_{\text {in }}=120 \mathrm{~V}$ and $V_{\text {out }}=48 \mathrm{~V}$ at $P_{\text {out }}=10 \mathrm{~W}$ is experimentally validated. Moreover, the waveforms in steady state are displayed. Then, we validate the regulation against the load variation. Finally, we conclude about this present and future works.

\section{Topology description}

The DC-DC converter is presented in Fig. 1. As shown, the converter is composed of a high quality factor piezoelectric resonator (PR), four diode $\mathrm{D}_{\{1,2,3,4\}}$ and two NMOS FET switches $\mathrm{S}_{1}$ and $\mathrm{S}_{2}$. The PR is modeled by a capacitance $C_{P}$ in parallel with a $L-C-R$ motional branch, the electrical equivalent circuit is displayed in Fig.2a. The material of the PR used in this converter is Lead Zirconate Titanate (PZT), this ceramic offers high quality factor and high coupling factor (see Table I). In inductive region (near the resonant frequency) [9], the motional LCR branch can be modeled by a sinusoidal current source $i$ in series with the resistance $R_{p}$ (Fig.2b). Because we consider a step-down converter, the inputoutput voltage gain should not exceed $0.5\left(V_{\text {in }}>2 V_{\text {out }}\right)$. This topology allows establishing three possible voltages on the PR: $V_{\text {in }}-V_{\text {out }},-V_{\text {out }}$ and $+V_{\text {out }}$. During these connections, the PR exchanges energy with the input source and the output load. Moreover, the PR can operate in open-circuit mode. In this mode, no electrical charges are exchanged with the outside and the motional branch's sinusoidal current charges/discharges the parallel capacitance $C_{P}$ and makes the voltage $V_{P}$ progressively change, as show in Eq.1. Thanks to this mode, the voltage $V_{P}$ evolves naturally to the next constant voltage level and permit to switch-on $\mathrm{S}_{1}$ and $\mathrm{S}_{2}$ when the voltage across them reaches $0 \mathrm{~V}$ (soft switching operation), leading to reduced switching losses. Indeed, in steady state, the PR stores electrical energy when connected to $V_{\text {in }}-V_{\text {out }}$ as an increase of mechanical energy. This mechanical energy is then released as electrical energy when PR is connected to $V_{\text {out }}$ or $-V_{\text {out }}$ (depending on the sign of current). 


$$
\begin{aligned}
& V_{P}(t)=-\frac{1}{C_{P}} \int i(t) \cdot d t \\
& i(t)=I \cdot \sin (\omega \cdot t)
\end{aligned}
$$

$V_{P}$ is the PR's voltage, $i$ is the motional branch internal current, $I$ is its amplitude, $\omega(\mathrm{rad} / \mathrm{s})$ is the pulsation of the conversion period.



Fig. 1: Converter topology.

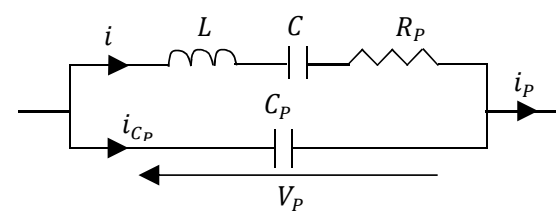

(a)

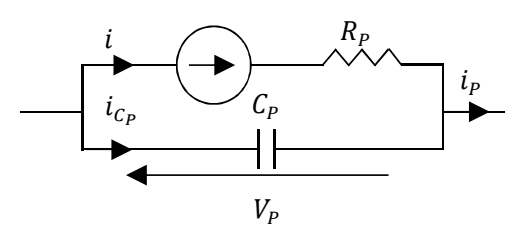

(b)

Fig. 2: Electrical model for PRs, (a) Circuit model [15], (b) Electrical model in inductive region.

\section{Energy conversion cycle}

The conversion cycle is presented in Fig. 3. It is composed of 6 steps, which alternates constant voltage and constant charge. Each stage is represented in Fig. 3 with the cycle timeline. We separate step 6 in steps $6 . \mathrm{a}$ and $6 . \mathrm{b}$ in order to separate the part before and after the sign of the current $i$ changes. The $6^{\text {th }}$ step has for objective to let the piezoelectric voltage $V_{P}$ goes from $V_{\text {out }}$ to $V_{\text {in }}-V_{\text {out }}$, then as soon as $V_{P}$ reaches $V_{\text {in }}-V_{\text {out }}$ the switch $S_{1}$ should be closed. However, the Drain-Source voltage of $\mathrm{S}_{1}$ is not null but equals to $V_{\text {out }}$ which induces power losses, since the diode $\mathrm{D}_{3}$ was in conduction just before. To overcome that limitation and ensure ZVS condition, we let $V_{P}$ goes up to $V_{\text {in }}$ before going back to $V_{\text {in }}-$ $V_{\text {out }}$ during the stage $6 . \mathrm{b}$ with a voltage approaching 0 across $\mathrm{D}_{4}$ and across $\mathrm{S}_{1}$ at $t=t_{0}$.

In Fig. 4, we represent the voltage $V_{P}$ in function of the transfer electrical charges for a single conversion cycle. In the diagram $V_{P}$ vs $Q$, the horizontal displacements correspond to the connected phases since $V_{P}$ is constant, and the vertical displacements correspond to the isolated phases since no electrical charge is exchanged with the input source or output load. Moreover, for a displacement in positive sense, the transferred electrical charge is positive value, and for displacement in negative sense, the transferred electrical charge is negative. The area under the curve represent the electrical energy exchanged with the PR, as shown in Fig.4. The diagram $V_{P}$ vs $Q$ allow to more understanding the operating principle. Using the $V_{P}$ vs $Q$ representation enable to construct any switching sequences by alternating horizontal 
displacement and vertical displacement with ensured closed diagram. This representation allow to easily visualizing and understanding the energy and electrical charge transferred.

In steady state, over a full conversion cycle, the energy and electrical charges are balanced, inducing a constant oscillation amplitude. The energy transfer with the PR operates during constant voltage $V_{P}$. Therefore, the conservation of energy $(\mathrm{CoE})$ during each cycle is given by Eq.3, while $E_{\text {in }}$ is the electrical energy stored when the PR is connected to $V_{\text {in }}-V_{\text {out }} . E_{\text {out }}$ is the electrical energy restored to the load, when the PR is connected to $-V_{\text {out }}$ and $+V_{\text {out }}$. Energy losses due to the PR's resistance are taken into account by Eq. 3 and Eq. 4 .

$$
\begin{aligned}
& E_{\text {in }}+E_{\text {out }}+E_{P R_{\text {losses }}}=0 \\
& E_{P R_{\text {losses }}}=-\frac{1}{2} R_{P} I^{2} T
\end{aligned}
$$

$\mathrm{T}$ : conversion cycle duration. (All values are algebraic)

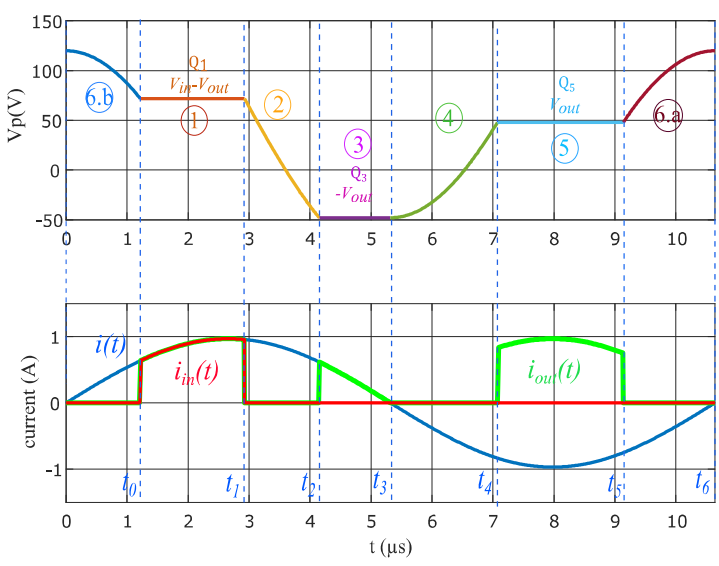

Fig. 3: Waveform of the PR's voltage and currents for $1-6 \mathrm{~b}$ phases: $V_{\text {in }}=120 \mathrm{~V}$, $V_{\text {out }}=48 \mathrm{~V}$ and $P_{\text {out }}=10 \mathrm{~W}$. (Red: $i_{\text {in }}$, Blue: $i$, Green: $i_{\text {out }}$ )

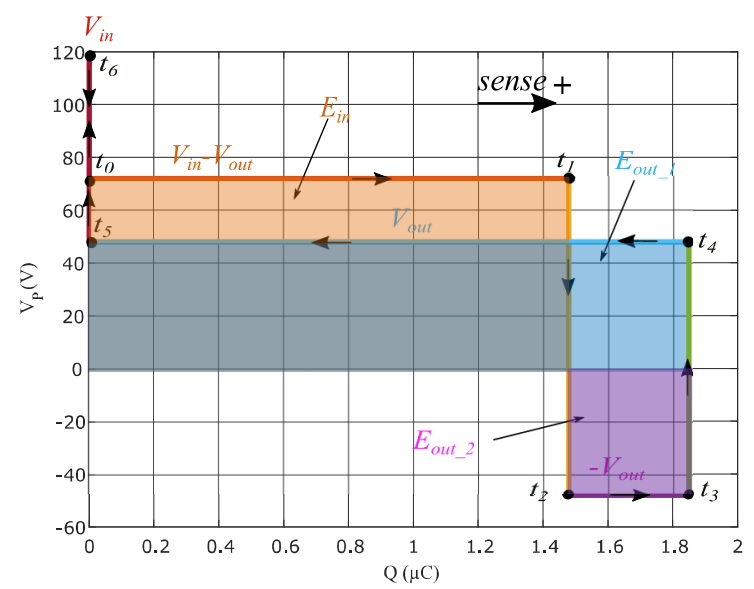

Fig.4: Voltage Vs Electrical charge of PR for 1-6b phases: $V_{\text {in }}=120 \mathrm{~V}, V_{\text {out }}=48 \mathrm{~V}$ and $P_{\text {out }}=10 \mathrm{~W}$.

The conservation of electrical charge (CoC) during a cycle of conversion is given by Eq.5:

$$
Q_{1}+Q_{3}+Q_{5}=0
$$

$Q_{1}, Q_{3}$ and $Q_{5}$ are the algebraic electrical charges for stage 1,3 and 5 respectively.

We can determine each transition time $\left(t_{0}, t_{1} \ldots t_{6}\right)$ of the cycle by combining the above equations in steady state and considering PR's electrical model, assuming a constant output voltage and operating in soft switching. As shown in Fig. 3, we solved the previous equations for input voltage $120 \mathrm{~V}$, output voltage $48 \mathrm{~V}$ and output power $10 \mathrm{~W}$ by using the electrical parameters of the PR that are listed in Table 1. Then, we have calculated each transition time for each phase. The electrical parameters of the PR are obtained experimentally by using an impedance analyzer.

Table I: Characteristics of the electrical model of PR. (Part NO: Z0.75T25D-W (C-213). Material is Lead Zirconate Titanate (PZT), the diameter is $25 \mathrm{~mm}$, and thickness is 0.75 $\mathbf{m m}$, the supplier is FUJITSU)

\begin{tabular}{|l|c|c|c|c|c|c|c|}
\hline & $\mathrm{L}$ & $\mathrm{C}$ & $\mathrm{R}_{\mathrm{P}}$ & $\mathrm{C}_{\mathrm{P}}$ & $\mathrm{f}_{\mathrm{r}}$ & $\begin{array}{c}\text { Quality factor } \\
\mathrm{Q}\end{array}$ & $\begin{array}{c}\text { Coupling factor } \\
\mathrm{k}\end{array}$ \\
\hline Value & $1.1 \mathrm{mH}$ & $2.9 \mathrm{nF}$ & $0.6 \Omega$ & $8.4 \mathrm{nF}$ & $89 \mathrm{kHz}$ & 1000 & $52 \%$ \\
\hline
\end{tabular}




\section{Control strategy of the DC-DC converter}

In this section, we propose an analysis of the control strategy in order to regulate the output voltage. As demonstrated in the previous section, in steady state, we should achieve the $\mathrm{CoE}, \mathrm{CoC}$ and the operating in ZVS conditions to reduce losses. Therefore, the objective of the control is also to regulate the output voltage with high efficiency.

\section{Synchronization with the current $i$}

Since, the PR resonates at variable frequency, which is highly depending on the output power and on the parasitic capacitances of switches [9-10]. The resonance frequency and the phase of the internal current $i$ should be well known in order to synchronize the drive of switches $\mathrm{S}_{1}$ and $\mathrm{S}_{2}$ (as shown in Fig.3). In this purpose, we propose to use the state of diode $\mathrm{D}_{3}$ to detect the 0 crossing of the internal current $i$ and deduce the resonant period duration Therefore, when current $i$ is positive, diode $\mathrm{D}_{3}$ is turned-off, and -on when negative. Hereunder, we will consider that the switches driving is synchronized with the internally current thanks to monitoring the state of $\mathrm{D}_{3}$.

\section{Zero Voltage Switching}

In order to operate in soft switching, we have to detect the zero voltage crossing of switches $\mathrm{S}_{1}$ and $\mathrm{S}_{2}$. For switching-on $\mathrm{S}_{2}$, we simply turn it-on at the half period of the conversion cycle (as shown in Fig. 3 ), when the voltage of the PR equals $-V_{\text {out }}$. For switching-on $\mathrm{S}_{1}$, we have to regulate $t_{5}$ to let voltage $V_{P}$ reaching the input voltage value $V_{i n}$ at the end of the period. Indeed, if $\mathrm{t}_{5}$ is superior to the optimal value $t_{5 \_ \text {opt }}$ (the value to achieve ZVS for $\mathrm{S}_{1}$, see in Fig. 3 ), then voltage $V_{P}$ will not have time enough to reach $V_{i n}$. Alternatively, if $t_{5}$ is inferior to the optimal value $t_{5 \_ \text {opt }}$, the voltage $V_{P}$ will reach $V_{\text {in }}$ before the end of the cycle and the voltage will be clamped by the body diode of $\mathrm{S}_{1}$, and a part of energy is restored to the input source that inducing unnecessary losses. Wherefore, a simple comparator can be used to regulate $t_{5}$ for the next conversion cycle by comparing the voltage $V_{D_{1}}$ (left side of $V_{P}$ ) with input voltage $V_{\text {in }}$ (see Fig. 5).

\section{Output voltage regulation}

As displayed in Fig. 3, the PR takes energy from the input source during step 1; in fact, the instant $t_{1}$ controls the amount of energy exchanged. By considering a resistor load $R_{\text {Load }}$ in parallel with a capacitor $C_{\text {out }}$ that filter the output voltage, we can deduce a relation between $t_{l}$ and $V_{\text {out }}$. Equation 6 gives the relation between $t_{l}$ and $V_{\text {out }}$.

$$
\cos \left(\omega * t_{1}\right)=1-4 \frac{V_{\text {out }}}{V_{\text {in }}}+V_{\text {out }} \frac{C_{P} \omega}{I}\left(1+2 \frac{V_{\text {out }}}{V_{\text {in }}}\right)-\pi \frac{R_{P} I}{V_{\text {in }}}
$$

$\omega(\mathrm{rad} / \mathrm{s})$ is the resonant pulsation of the PR, which is synchronized the switches driving. $V_{i n}$ is the input voltage and considered constant $\left(V_{i n}=120 \mathrm{~V}\right), I$ is the amplitude of the internal current $i$ that is also considered constant. So, only $t_{1}$ and $V_{\text {out }}$ are variables. By using small signals modeling, we can deduce a gain expression between $t_{1}$ and $V_{\text {out }}$. Then, a proportional-integral (PI) controller can be designed to regulate the output voltage by adjusting the instant $t_{1}$.

For ease of understanding, we have represented the control strategy in the block diagram depicted in Fig.5. Thus, to implement the control, we need a comparator for current sign detection to monitor the state of $\mathrm{D}_{3}$ in order to synchronize the switching sequence with the current waveform. A second comparator compare $V_{D_{1}}$ with $V_{i n}$ at the end of period to ensure $\mathrm{ZVS}$ operation on $\mathrm{S}_{1}$. For output voltage regulation, the difference between the measured $V_{\text {out }}$ and the reference is multiplied by a PI controller to calculate $t_{1}$. As shown Fig. 5 , the switches $\mathrm{S}_{1}$ is turned on at $\mathrm{t}=\mathrm{t}_{0}$ with ZVS. Then, $V_{P}$ decrease from $V_{\text {in }}$ to $V_{\text {in }}-V_{\text {out }}$. Ones $V_{P}=V_{\text {in }}-V_{\text {out }}$, the diode $\mathrm{D}_{4}$ is turned on, and PR takes energy from input source until to turn off $\mathrm{S}_{1}$ at $\mathrm{t}=\mathrm{t}_{1}$ in order to regulate $V_{\text {out }}$. During $\left[\mathrm{t}_{1}, \mathrm{t}_{2}\right], V_{P}$ decrease from $V_{\text {in }}-V_{\text {out }}$ to $-V_{\text {out }}$. When $V_{P}=-V_{\text {out }}$, the diodes $\mathrm{D}_{1}$ and $\mathrm{D}_{4}$ are turned on naturally, and part of the stored energy in PR is transferred the output load until the current $i$ becomes negative. When $\mathrm{t}=\mathrm{t}_{3}$, the switches $\mathrm{S}_{2}$ is turned on, and the voltage $V_{P}$ goes from $-V_{\text {out }}$ to $V_{\text {out }}$. Ones $V_{P}=V_{\text {out }}$, the diode $\mathrm{D}_{2}$ and $\mathrm{D}_{3}$ are turned on, and the second part of the stored energy in PR is restored to output load. This phase ends by turning off $\mathrm{S}_{2}$ at $\mathrm{t}=\mathrm{t}_{5}$ in order to let the voltage $V_{P}$ evolve to reach $V_{\text {in }}$ at the end of period. 


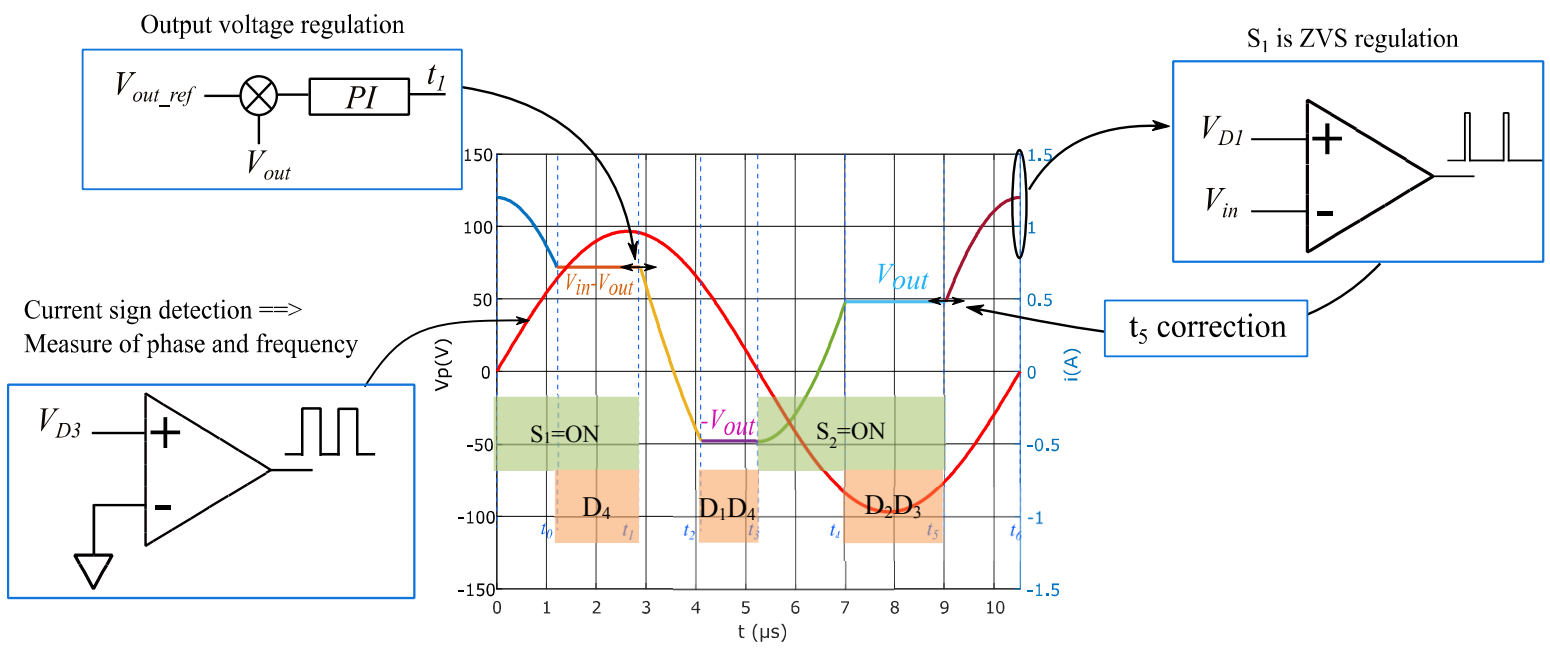

Fig. 5: Control diagram of the circuit.

\section{Experimental Results}

\section{Setup}

An actual power converter circuit is designed in the aim to test the proposed control strategy. Components references used in the prototype are listed in Table II. Figure 6 shows the prototype that is composed of two PCB circuits; power circuits and FPGA board. The control strategy is modeled in VHDL language and implemented in a FPGA SPARTAN 3 (XC3S200) design kit. The $230 \Omega$ load resistance is calculated for $48 \mathrm{~V} / 10 \mathrm{~W}$ output voltage and power. The output capacitor is chosen to reduce high frequency ripple of $V_{\text {out }}$, the value of $C_{\text {out }}$ is $10 \mu \mathrm{F}$. The output voltage is sensed by a voltage divider and then digitalized with an analog digital converter (ADC) AMC1204. The difference between the voltage reference and the measured output voltage enables to calculate the time duration $t_{1}$ by using a PI regulator, which is digitalized and implemented in the FPGA on state-machine. The FPGA receives measurements from the power circuit, and then calculates the variables $t_{1}, t_{5}$ and $f$. Ones this variables are calculate the FPGA generates the width modulated pulse (PWM) synchronized with the internal PR current phase.

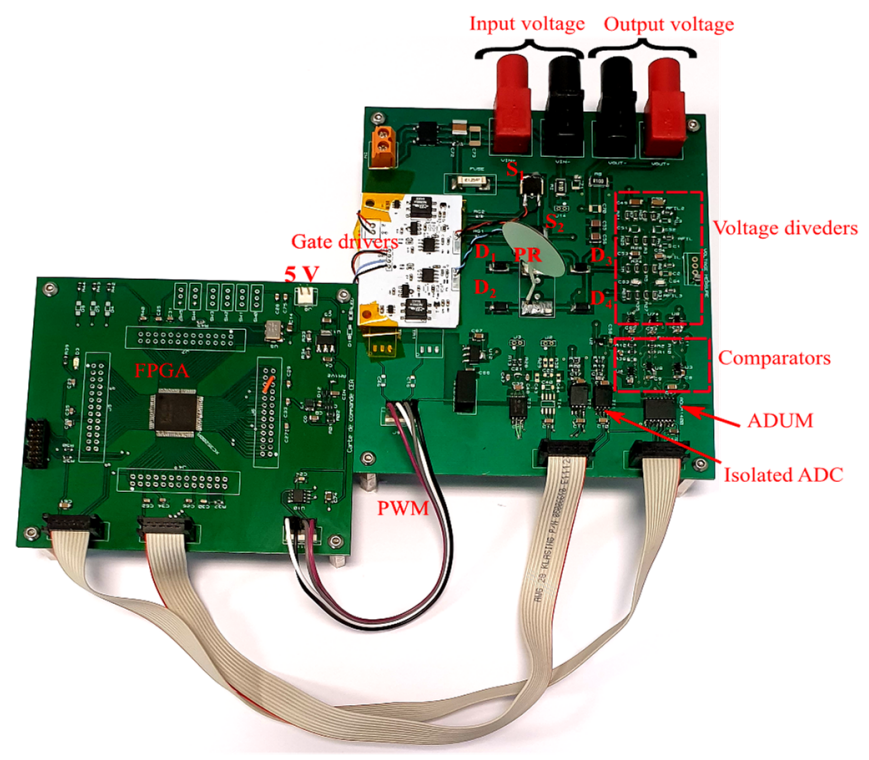

Fig. 6: Prototype circuit. 
Table II: Reference of power components

\begin{tabular}{|l|c|c|c|}
\hline & MOSFET Switch (S1, S2) & Diode (D1, D2) & Diode (D3, D4) \\
\hline Reference & STD5NM50T4 & US1G & VSSB310 \\
\hline
\end{tabular}

\section{Experimental waveforms}

\section{Dynamic response}

Figure 7 shows the dynamic response for an input voltage of $120 \mathrm{~V}$ and an output voltage of $48 \mathrm{~V}$, the output power is $10 \mathrm{~W}$. As shown in Fig. 7, the converter operates firstly in open loop to increase the amplitude of oscillation, in order to detect the 0 current crosses and to measure the frequency of the PR. During this phase, the oscillation amplitude is not monitored because the switching sequences is not synchronized with the internal current. In a second step, the regulation is turned-on. As shown, the amplitude of oscillations decreases and the output voltage is regulated to the reference value. The settling time is $1.2 \mathrm{~ms}$ for the output voltage reach $90 \%$ of voltage reference. The conversion cycle is presented in steady state in the upper right part of Fig.7. The experimental waveform $V_{P}$ is matching with the theoretical one (see Fig.3). The current $i_{p}$ displayed in Fig. 7 represents the internal current $i$ measured during only the constant voltage, since no current flow during isolated phases. From the waveform of $i_{p}$, we can deduce the instantaneous current of $i_{\text {in }}$ and $i_{\text {out }}$. Indeed, $i_{\text {in }}$ equals current $i_{p}$ during phase 1 , and $i_{\text {out }}$ is the current $i_{p}$ during phase 1 , phase 3 and $-i_{p}$ during phase 5 . Moreover, the waveform of the internal current $i$ can be approximated by a sinusoidal curve, as shown in Fig.7. We have measured $94.05 \%$ of efficiency at $10 \mathrm{~W}$ output power for $120 / 48 \mathrm{~V}$ input-output voltage considering only the power circuit. We have measured $1.1 \mathrm{~W}$ at $5 \mathrm{~V}$ power supply for the FPGA and the driving stage, which is quite high for our application, but no optimization was done for this circuit (out of the scope of this paper). However, the high efficiency and power densities of PRs-based converters could motivate the investigation in optimization of integrated digital controller (ASIC) with low cost and low power consumption.

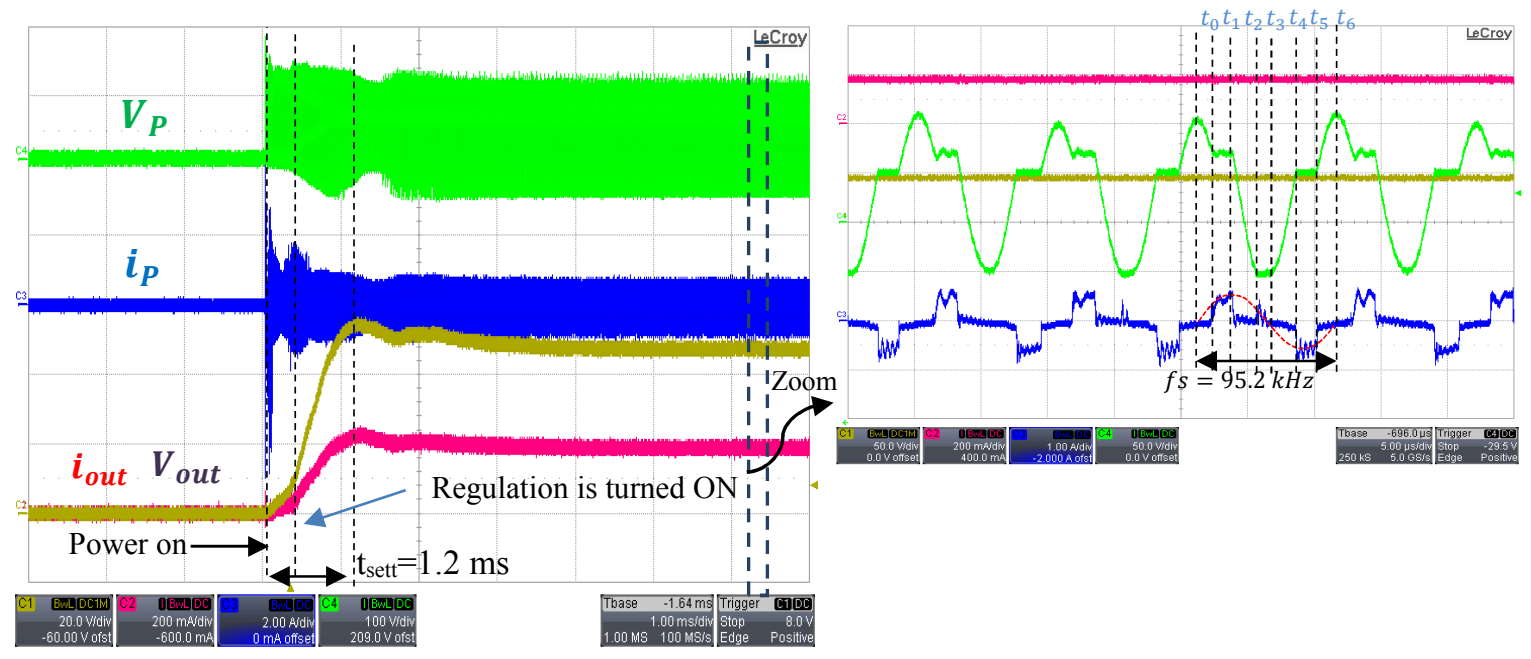

Fig. 7: Experimental dynamic response for input voltage $120 \mathrm{~V}$ and output voltage $48 \mathrm{~V}$ at $10 \mathrm{~W}$.

\section{Load variation}

The load transient is examined for load variation. Fig. 8(a) shows a step change in load from $7 \mathrm{~W}$ to 13 $\mathrm{W}$, and the output current goes from $0.145 \mathrm{~A}$ to $0.27 \mathrm{~A}$. We can see that the output voltage $V_{\text {out }}$ falls by $6 \mathrm{~V}$ before going back to the voltage reference when the load variation is applied. The output voltage is then regulated after $2.2 \mathrm{~ms}$. Moreover, the resonance frequency decreases from $96.9 \mathrm{kHz}$ to $94.3 \mathrm{kHz}$, as the amplitude of the oscillation increases on current $i_{p}$. It is noted that during the transient response, the switching driving still synchronized with the resonance period of the PR since no overshoot of 
current $i_{P}$ is observed. Fig. $8(\mathrm{~b})$ shows a step change in load from $13 \mathrm{~W}$ to $7 \mathrm{~W}$. In this case, the overshoot of the output voltage is less than $2 \mathrm{~V}$ and the output current $i_{p}$ reaches the desired $0.145 \mathrm{~A}$ value after $2.5 \mathrm{~ms}$. We can also observe an overshoot on current $i_{P}$ because no ZVS of $\mathrm{S}_{1}$ is ensured since voltage $V_{P}$ did not reach $V_{i n}$ at the end of the period. However, the regulation of $\mathrm{t}_{5}$ operates to ensure soft switching of $S_{1}$, as shown in steady state.

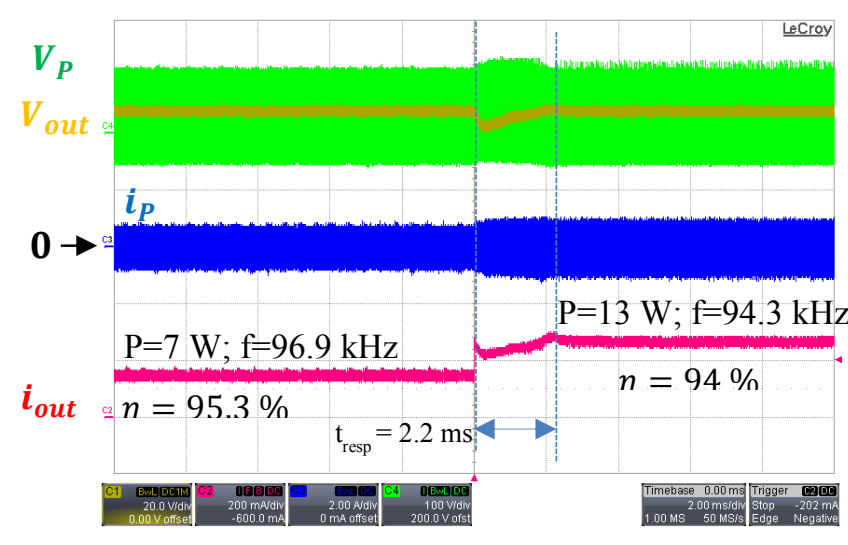

(a)

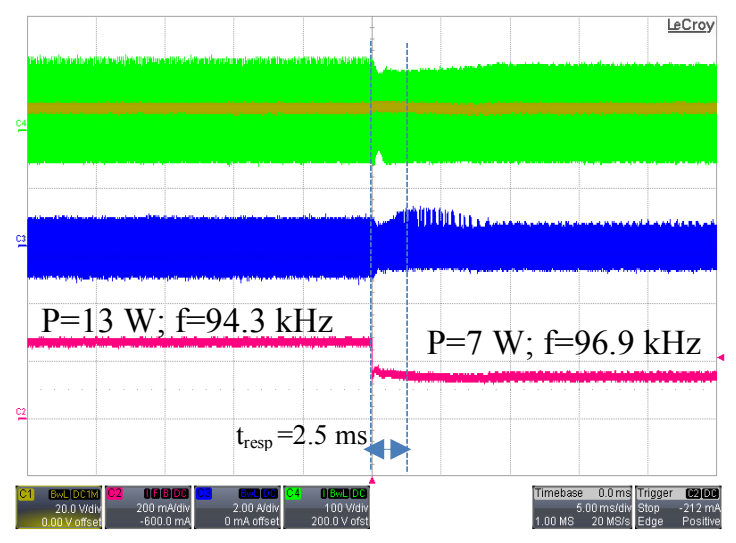

(b)

Fig. 8: Dynamic response for load variations.

\section{Efficiency}

Figure 9 shows the efficiency as a function of the output power for $V_{i n}=120 \mathrm{~V}$ and for different gain ratios up to $\frac{V_{\text {out }}}{V_{\text {in }}}=0.4$. Experimentally, we have noted that the maximum output power for our PR is limited by the amplitude of the PR current $I(\approx 1 \mathrm{~A})$ due to the rise of temperature. So, increasing the output voltage will increase the maximum output power allowed, as shown in Fig.9. For a fixed input voltage, the efficiency increases when the output voltage increased as the amplitude of the current decreases, which decreases the power losses by $I^{2}$. We have obtained an efficiency higher than $94 \%$ for large operating power range and a peak efficiency of $96 \%$ is obtained for $\frac{V_{\text {out }}}{V_{\text {in }}}=0.4$ and $P_{\text {out }}=8 \mathrm{~W}$.

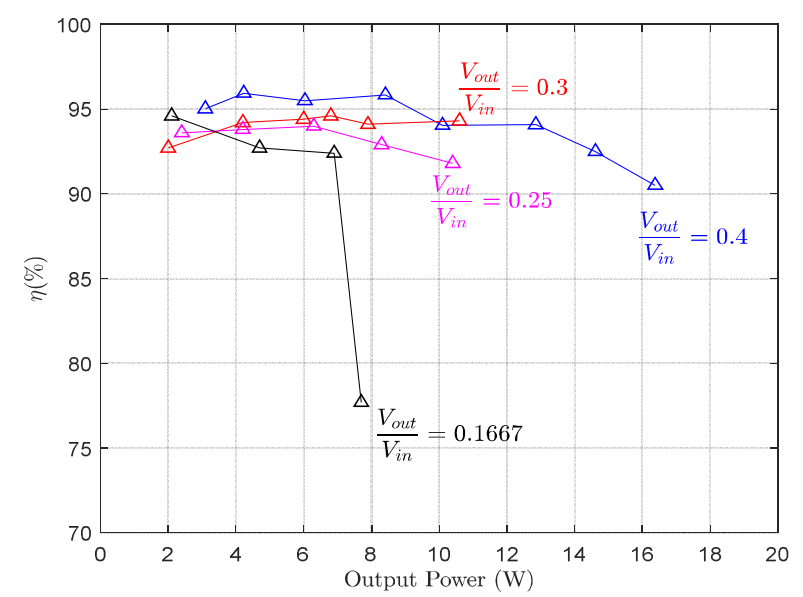

Fig. 9: Efficiency Vs Output Power for $V_{\text {in }}=120 \mathrm{~V}$ and for different gain ratios up to $\frac{V_{\text {out }}}{V_{\text {in }}}=0.4$.

\section{Conclusion and future works}

The concept to control a new DC-DC step-down converter based on a piezoelectric resonator is introduced in this paper. The conversion principle is explained in details. The control strategy is modeled and implemented in a FPGA. The operating with good performances is verified. Furthermore, our 
specific control strategy enables to regulate efficiently the output at any voltage between $0 \mathrm{~V}$ to $\frac{V_{\text {in }}}{2}$ in less than $1.4 \mathrm{~ms}$. Experimental results validated both the dynamic response and the steady state operations. Efficiency up to $94.05 \%$ has been measured at $10 \mathrm{~W}$ and at input-output voltages of 120 $48 \mathrm{~V}$.

This paper demonstrate the feasibility of controlling dc-dc converter based on PR by using commercial components, however, we can reduce consumption and increase performances by integrating the control circuit into an ASIC, which is one of the scopes of our lab. The principle using PZT PR in DC-DC converters makes it an excellent solution for very compact, high input voltage, low output voltage applications at low power and high efficiency. Many opportunities still have to be explored such as serialization and/or parallelization of PRs to increase the power. As a conclusion, this new operating principle gives new opportunities in power electronics with the aims of miniaturizing and integration. It could be a serious challenger for magnetic and electrostatic based converters.

\section{References}

[1] C. R. Sullivan, B. A. Reese, A. L. F. Stein and P. A. Kyaw, "On size and magnetics: Why small efficient power inductors are rare," 2016 International Symposium on 3D Power Electronics Integration and Manufacturing (3D-PEIM), Raleigh, NC, 2016, pp. 1-23.

[2] S. Ghandour, G. Despesse and S. Basrour, "Design of a new MEMS DC/DC voltage step-down converter" Proceedings of the 8th IEEE International NEWCAS Conference 2010, Montreal, QC, 2010, pp. 105-108.

[3] S. V. Cheong et al., "Inductorless DC-to-DC Converter with High Power Density", IEEE Trans. Ind. Electronics, vol. 41, no.2, 1994.

[4] M. S. Makowski and D. Maksimovic, "Performance limits of switched-capacitor DC-DC converters," Proceedings of PESC '95 - Power Electronics Specialist Conference, Atlanta, GA, USA, 1995, pp. 1215-1221vol.2.

[5] R. Schulze et al., "Integration of piezoelectric polymer transducers into microsystems for sensing applications" Proceedings of ISAF-ECAPD-PFM 2012, Aveiro, 2012, pp. 1-4.

[6] S. Shanmugavel et al., "Miniaturized acceleration sensors with in- plane polarized piezoelectric thin films produced by micromachining," IEEE Transactions on Ultrasonics, Ferroelectrics, and Frequency Control, vol. 58, no. 11, pp. 2289-2296, November 2011.

[7] M. Ekhtiari, Z. Zhang and M. A. E. Andersen, "State-of-the-art piezoelectric transformer-based switch mode power supplies," IECON 2014 - 40th Annual Conference of the IEEE Industrial Electronics Society, Dallas, TX, 2014, pp. 5072-5078.

[8] S. Moon and J.-H. Park, "High power DC-DC conversion applications of disk-type radial mode $\mathrm{Pb}(\mathrm{Zr}, \mathrm{Ti}) \mathrm{O} 3$ ceramic transducer,”Jpn. J. Appl. Phys., vol. 50, no. 9, Sep. 2011, Art. no. 09ND20.

[9] B. Pollet, F. Costa and G. Despesse, "A new inductorless DC-DC piezoelectric flyback converter" 2018 IEEE International Conference on Industrial Technology (ICIT), Lyon, 2018, pp. 585-590.

[10] B. Pollet, G. Despesse and F. Costa, "A New Non-Isolated Low-Power Inductorless Piezoelectric DCDC Converter," in IEEE Transactions on Power Electronics, vol. 34, no. 11, pp. 11002-11013, Nov. 2019.

[11] J. D. Boles, J. J. Piel and D. J. Perreault, "Enumeration and Analysis of DC-DC Converter Implementations Based on Piezoelectric Resonators," 2019 20th Workshop on Control and Modeling for Power Electronics (COMPEL), Toronto, ON, Canada, 2019, pp. 1-8.

[12] Thenathayalan, Daniel, Chun-gu Lee and Joung-Hu Park. "Battery voltage-balancing applications of disktype radial mode $\mathrm{Pb}(\mathrm{Zr} \cdot \mathrm{Ti}) \mathrm{O} 3$ ceramic resonator,” 2017 Japanese Journal of Applied Physics. 56.

[13] M. Touhami, B. Pollet, G. Despesse, and F. Costa, "A new dc-dc piezoelectric converter," 9th National Days on Energy Harvesting and Storage (JNRSE), May 2019.

[14] M. M. Jovanovic, K. Liu, R. Oruganti and F. C. Y. Lee, "State-Plane Analysis of Quasi-Resonant Converters," in IEEE Transactions on Power Electronics, vol. PE-2, no. 1, pp. 36-44, Jan. 1987.

[15] K. S. Van Dyke, "The piezo-electric resonator and its equivalent network," Proceedings of the Institute of Radio Engineers, vol. 16, no. 6, pp. 742-764, June 1928. 